\title{
Analysis of drought areas in northern Algeria using Markov chains
}

\author{
Mourad Lazri ${ }^{1, *}$, Soltane Ameur, Jean Michel Brucker ${ }^{2}$, \\ Mourad LAHDiR ${ }^{1}$ and Mounir SeHAD ${ }^{1}$ \\ ${ }^{1}$ Laboratoire LAMPA, University of Tizi Ouzou, Tizi Ouzou, Algeria. \\ ${ }^{2}$ School EPMI, EPMI - 13 Boulevard de l'Hautil 95092 CERGY PONTOISE Cedex, Paris, France. \\ ${ }^{*}$ Corresponding author.e-mail: m_lazri@yahoo.fr
}

The present work studies the trends in drought in northern Algeria. This region was marked by a severe, wide-ranging and persistent drought due to its extraordinary rainfall deficit. In this study, drought classes are identified using SPI (standardized precipitation index) values. A Markovian approach is adopted to discern the probabilistic behaviour of the time series of the drought. Thus, a transition probability matrix is constructed from drought distribution maps. The trends in changes in drought types and the distribution area are analyzed. The results show that the probability of class severe/extreme drought increases considerably rising from the probability of 0.2650 in 2005 to a stable probability of 0.5756 in 2041.

\section{Introduction}

Global warming and climate change refer to an increase in average global temperatures, which causes a change in the amount and pattern of precipitation and consequently facilitates the installation of the drought. The increase in the GHGs (greenhouse gases) is an underlying cause of the global warming. Indeed, the increased amount of gases which absorb heat, has directly lead to more heat being retained in the atmosphere and thus an increase in global average surface temperatures.

Drought is an extreme recurrent climatic event characterized by lower than normal precipitation. Although it occurs in all climatic zones, its characteristics vary significantly from one region to another. Drought conditions can have critical environmental and economical impacts, especially in areas with high water demand and intensive agricultural activity.

In Algeria, the coincidence of an annual rainfall minimum with a maximum in evapotranspiration, due to the high temperatures in summer, leads to a depletion of the water reserves available for plants and the onset of many mechanisms of adaptation designed to combat this type of situation (water stress). This circumstance may also aggravate the effects of other environmental problems typical of the region, such as the intensity and frequency of forest fires (Alexandrian et al. 1999) and processes deriving from soil degradation and loss (De Luis et al. 2000).

In this context, studies analyzing the intensity and frequency of dry spells are necessary in regions such as the one studied here, where water resources are scarce and ecosystems show greater sensitivity to water availability. Therefore, it is important to develop prediction tools, including probabilistic ones, which may support timely implementation of preparedness and mitigation measures. In recent years, many statistical studies have been conducted to evaluate drought by analyzing the occurrence or nonoccurrence of rainfall (e.g., Moon et al. 1994; Mehrotra and Sharma 2005; Mehrotra et al. 2006;

Keywords. Drought; rainfall; Markov chain; transition probabilities; standardized precipitation index. 
Lazri et al. 2007; Yoo et al. 2012), but fewer studies have been conducted to evaluate drought change trend in future and the spatiotemporal evolution of drought. In addition, the use of remote sensing technology from satellite imagery allows improving the identification, inventory, mapping, and classification of land wetlands and increased spatial coverage. The SPI (standardized precipitation index) developed by McKee et al. $(1993,1995)$ is widely used for the identification of drought events and to evaluate its severity (e.g., Moreira et al. 2006, 2008; Cancelliere et al. 2007).

Among the different probabilistic approaches, Markov chain models are a frequent choice in the published literature (e.g., Paulo and Pereira 2007; Chattopadhyay et al. 2012). For example, Gabriel and Neumann (1962) used a first-order stationary Markov chain. The models have since been extended to allow for nonstationarity, both by fitting separate chains to different periods of the year and by fitting continuous curves to the transition probabilities (Stern and Coe 1984). The order of Markov chain required has also been discussed extensively (Chin 1977), with the obvious conclusion that different sites require different orders. The dominant trend over the years has been the increase in the number of states to improve the performance of Markov model (e.g., Srikanthan and McMahon 2001). For example, Lennartsson et al. (2008) modelled precipitation in Sweden using multiple step Markov chains. It is shown that a Markov chain of an order higher than one is required. The derived models are used to compute different weather indices. The distribution of the modelled indices and the empirical ones show good agreement, which supports the choice of the model. Paulo and Pereira (2007) applied Markov chains with four states to predict the SPI drought class transitions using both the homogeneous and nonhomogeneous formulations. The results of the application of the Markov models show the usefulness of adopting a nonhomogeneous formulation, which allows to differentiate predictions in relation to the initial month considered, thus understanding the probable evolution of a drought as influenced by the climate and, in particular, the seasonality of rainfall.

The main reason for the use of Markov model is that, in probability theory and statistics, a Markov process can be thought of as 'memoryless': loosely speaking, a process satisfies the Markov property if one can make predictions for the future of the process based solely on its present state just as well as one could know the process's full history (Gabriel and Neuman 1962; Caskey 1963; Weiss 1964).

Thus, a Markov process is suitable for drought analysis and simulation of its dynamic change. The overall objective of this study is to analyze drought characteristics in northern Algeria, based on the variability of the amount of precipitation measured from satellite imagery. Four states describing the drought intensity to analyze drought distribution areas during 2005-2012, namely no drought, mild drought, moderate drought, severe/extreme drought are identified according SPI values and used in this study.

The structure of this paper is as follows: the underlying datasets and methods are introduced in section 2. Section 3 gives a procedure of the application of the model and results. The paper is closed with some conclusions in section 4 .

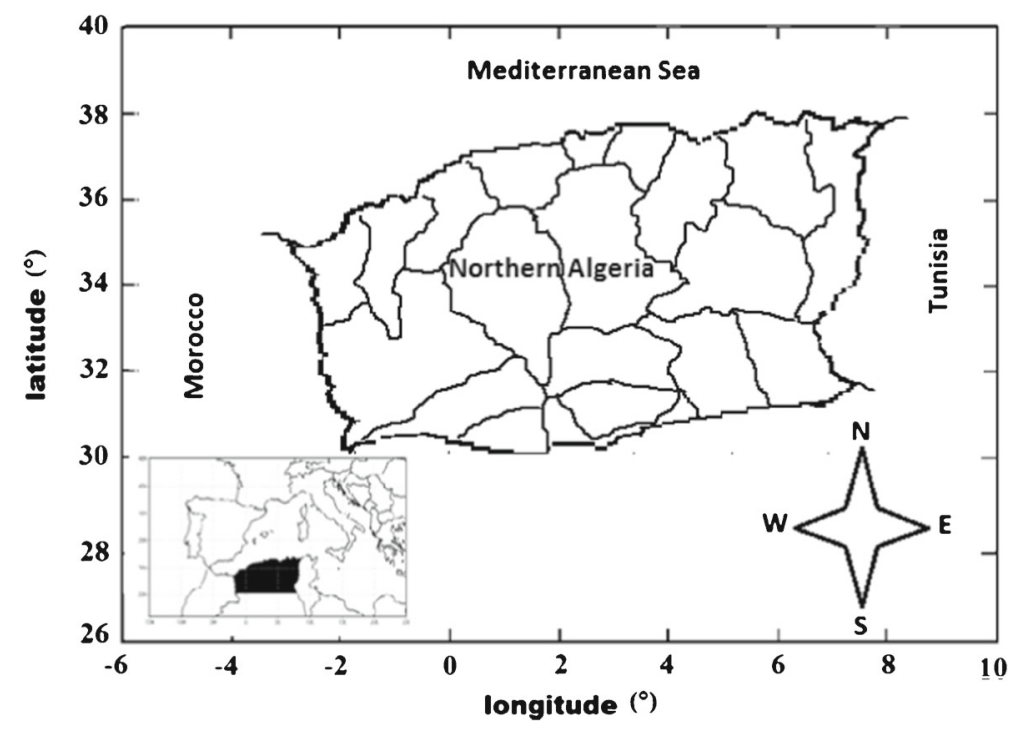

Figure 1. Study area. 
Table 1. Drought classes and corresponding SPI values.

\begin{tabular}{ll}
\hline Drought category & \multicolumn{1}{c}{ SPI values } \\
\hline No drought & $\geq 0$ \\
Mild drought & 0 to -0.99 \\
Moderate drought & -1.00 to -1.49 \\
Severe/extreme drought & $\leq-1.5$ \\
\hline
\end{tabular}

\section{Data and methods}

\subsection{Study area and data}

Algeria is located in North Africa and it forms, with Morocco and Tunisia, the southern edge of the Mediterranean. It covers a surface of 2381,740 $\mathrm{km}^{2}$, and is characterized by a well marked physical and climatic contrast between the north and south regions. It should be noted, however, that $75 \%$ of this expanse is a desert zone. The north of the country (figure 1) is characterized by a Mediterranean climate where the understanding and management of water is important. This area lies between the 30th and 37th parallels north. Majority of the population lives in this large zone $\left(582,320 \mathrm{~km}^{2}\right)$.

The distribution of precipitation is very heterogeneous. In fact, precipitation varies generally according to the relief and the distance from the sea. Average annual precipitation is $600 \mathrm{~mm}$. The areas which receive most rains are: the massif of Djurdjura and the massif of Edough, where the quantities of rain recorded exceed 1500 $\mathrm{mm}$ per year. From a temporal point of view, the annual precipitation cycle is very heterogeneous, with most rain falling between October and March. The summer is dry and lasts from May to September, when only some rare local storms are observed.

Annual precipitation maps from meteorological satellite data were calculated using the 'Convective/Stratiform Rain Area Delineation Technique (CS-RADT)' developed by Lazri et al. (2013) for 2005-2010 period. Rainfall estimates are validated by a network of about 219 rain gauges and radar precipitation (Lazri et al. 2013). It should be noted that the use of satellite data is to cover the entire northern part of Algeria unlike traditional data.

The satellite rainfall retrieval technique uses data from new European GEO satellite system based on the enhanced information content on optical and microphysical cloud properties provided by SEVIRI radiometer (Spinning Enhanced Visible and Infrared Imager) on Meteosat Second Generation (MSG). It relies on the conceptual model that precipitating clouds are characterized by a combination of particles that are large enough to fall, an adequate vertical extension, and the existence of ice particles in the upper part of the cloud. In other words, it is based on various spectral parameters of SEVIRI that express microphysical and optical cloud properties, which permit to distinguish between stratiform and convective clouds on the one hand and on the other hand, to estimate rainfall. The basic assumption is based on the relationship between infrared brightness temperature (BT) and convectively dominated precipitation areas, as well as the relationship between information about cloud properties and the stratiform precipitation areas, which became possible by the enhanced spectral resolution of the new generation GEO satellites.

MSG is a new series of European geostationary satellites that is operated by EUMETSAT. The first MSG Meteosat-8 is a spinning stabilized satellite that carries the 12-channel SEVIRI instrument with three channels at visible and near-infrared wavelengths between 0.6 and $1.6 \mu \mathrm{m}$, eight channels at infrared wavelengths between 3.8 and 14 $\mu \mathrm{m}$, and one high-resolution visible channel. The nadir spatial resolution of SEVIRI is $1 \times 1 \mathrm{~km}^{2}$ for the broadband high-resolution channel and $3 \times 3$ $\mathrm{km}^{2}$ for the other channels. Over northern Algeria, the satellite viewing zenith angle of SEVIRI is about $45^{\circ}$, and as a consequence, the spatial resolution is reduced to about $4 \times 5 \mathrm{~km}^{2}$.

On annual precipitation maps over northern Algeria, drought categories are classified according to SPI values (table 1 ). The SPI values were calculated based on 12-monthly rainfall values. The time scale of 12 months was selected as a medium length scale often used in drought studies, but any other scale could be used.

Thus, drought categories are divided into no drought, mild drought, moderate drought, severe drought and extreme drought areas using the respective thresholds of SPI proposed by McKee et al. (1993) and Paulo and Pereira (2007).

The SPI is widely used as an indicator of drought, because it has several advantages (Hayes et al. 1999). First, SPI is based on rainfall alone, so that drought assessment is possible even if other hydrometeorological measurements are not available. Second, it has a variable time scale and is thus conducive to describing drought conditions for a range of meteorological, hydrological, and agricultural applications. Third, its standardization ensures that the frequencies of extreme events at any location at any time scale are consistent.

Drought categories distribution area in northern Algeria (unit: $\mathrm{km}^{2}$ ) are given in table 2 and corresponding distribution maps are depicted in figure 2 for six times $(N)$ 2005, 2006, 2007, 2008, 2009, and 2010 . 
Table 2. Drought categories distribution area in northern Algeria.

\begin{tabular}{cccccc}
\hline Year & $\begin{array}{c}\text { No drought } \\
(\%)\end{array}$ & $\begin{array}{c}\text { Mild drought } \\
(\%)\end{array}$ & $\begin{array}{c}\text { Moderate } \\
\text { drought }(\%)\end{array}$ & $\begin{array}{c}\text { Severe/extreme } \\
\text { drought }(\%)\end{array}$ & $\begin{array}{c}\text { Total land area } \\
100 \%\left(\mathrm{~km}^{2}\right)\end{array}$ \\
\hline 2005 & 26 & 37 & 21 & 16 & 582320 \\
2006 & 25 & 38 & 16 & 21 & 582320 \\
2007 & 24 & 34 & 18 & 24 & 582320 \\
2008 & 23 & 33 & 20 & 24 & 582320 \\
2009 & 24 & 30 & 17 & 29 & 582320 \\
2010 & 23 & 29 & 16 & 32 & 582320 \\
\hline
\end{tabular}
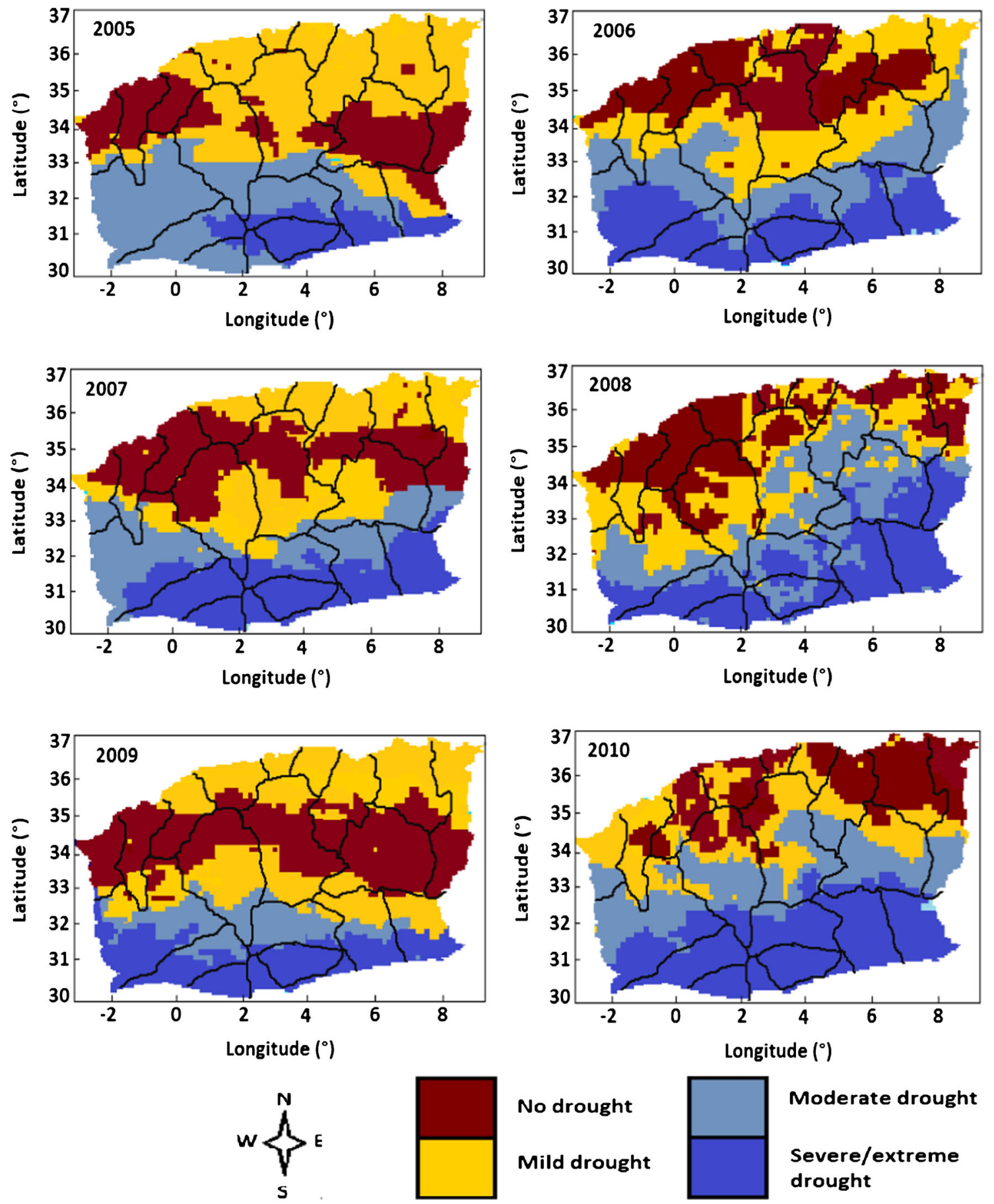

No drought

Mild drought

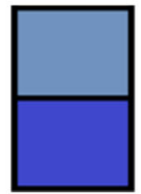

Moderate drought

Severe/extreme drought

Figure 2. Drought categories distribution maps. 
Table 3. Drought type area transition matrix.

\begin{tabular}{lrrrrr}
\hline & \multicolumn{4}{c}{2006} \\
\cline { 2 - 6 } 2005 & $\begin{array}{c}\text { No } \\
\text { drought }\end{array}$ & $\begin{array}{c}\text { Mild } \\
\text { drought }\end{array}$ & $\begin{array}{c}\text { Moderate } \\
\text { drought }\end{array}$ & $\begin{array}{c}\text { Severe /extreme } \\
\text { drought }\end{array}$ & Area total \\
\hline No drought & 119487 & 32983 & 1784 & 112 & 154366 \\
Mild drought & 16096 & 169890 & 22655 & 6961 & 215602 \\
Moderate drought & 6738 & 10842 & 60601 & 44908 & 123089 \\
Severe/extreme drought & 4443 & 4996 & 6459 & 73365 & 89263 \\
Area total & 146764 & 218711 & 91499 & 125346 & 582320 \\
\hline
\end{tabular}

Using drought categories distribution area (table 2), drought type area transition matrices have been determined for each transition of a year to another. As an illustration, transition matrix from 2005 to 2006 is given in table 3 .

\subsection{Methodology}

Droughts can be treated as stochastic events due to the random character of their contributing factors, and their probabilistic characterization is extremely helpful in water resources management. Advance warning and knowledge about the future evolution of a drought event can help to mitigate its consequences. In this context, the Markov model is used to analyze changes and trends in drought in the future in northern Algeria.

\subsubsection{Markov model}

(i) Markov chain: Markov chains are stochastic processes that can be parameterized by empirically estimating transition probabilities between discrete states in the observed systems (Çinlar 1975).

A Markov chain is characterized by a set of states, $S=\left\{S_{1}, S_{1}, \ldots, S_{r}\right\}$, and by the transition probability, $P_{i j}$, between states. The Markov chain of the first order is one for which each subsequent state depends only on the immediately preceding one.

The transition probability $P_{i j}$ is the probability that the Markov chain is at the next time point in state $j$, given that it is at the present time point in state $i$. The process can remain in the state it is in, and this occurs with probability $P_{i i}$. An initial probability distribution, defined as $Q(0)$, specifies the starting state.

(ii) Transition probability matrix: In general, for a Markov chain with $n$ states, there will be $n \times n$ transitions between two successive time instances. It is then possible to find the number of transition probabilities, $P_{i j}$ from a state at time $t$ to another state at time $t+1$. $P_{i j}$ can be arranged in sequence to give the following transition probability matrix:

$$
P=\left[\begin{array}{cccc}
\mathrm{P}_{00} \mathrm{P}_{01} & \ldots & . . & \mathrm{P}_{0 \mathrm{n}} \\
\mathrm{P}_{10} \mathrm{P}_{11} & \ldots & \ldots . & \mathrm{P}_{1 \mathrm{n}} \\
\ldots & \ldots & \ldots & \\
\mathrm{P}_{\mathrm{n} 1} \mathrm{P}_{\mathrm{n} 2} & \ldots & . . & \mathrm{P}_{\mathrm{nn}}
\end{array}\right]
$$

where $P_{i j}$ is the transition probability of state $i$ to state $j$.

According to Markov stochastic process theory, the probability matrix in the initial state can be used to calculate the state transition probabilities given from the initial state to the $n$th state and even a stable state. The formula of the $n$th state Markov transition probability was as follows:

$$
P_{i j}^{(n)}=\sum_{k=0}^{m-1} P_{i k}^{(n-1)} P_{k j}^{(n-1)}
$$

where $m$ is the number of rows or columns of the transition probability matrix, and the $n$th transition probability matrix is equivalent to the $n$th power of the first transition probability matrix.

To use Markov model, four assumptions should be supposed:

- The drought process is described by state space $S=\left\{S_{0}, S_{1}, S_{2}\right\}$; this is a Markov chain with finite state space.

- The evolution of phenomenon is random: it is a stochastic process.

- The future depends only on the present; it verifies the Markov property (no memory): this is a Markov chain.

- Possible developments of the process do not depend on time, the system verifies the homogeneity property: this is a homogeneous Markov chain.

(iii) Markov estimation: According to the theory of Markov stochastic process, the use of the initial probability distribution vector $Q(0)$ and the transition probability matrix $M$ permit to calculate the drought distribution area 
in northern Algeria in the future. The Markov simulation model $Q(n)$ is as follows:

$$
Q(n)=M^{(1)} Q(n-1)=M^{(n)} Q(0) .
$$

\section{Procedure and results}

The Markov model is applied to drought categories distribution maps. To do this, the initial state and transition probability matrix are determined.

\subsection{The initial state and the transition probability matrix}

The first step is the determination of the initial state matrix. As mentioned previously, the drought classes are divided into a set of states evolving mutually. Thus, the building of the initial state matrix with the areas of each drought category for 2005 is as follows (unit: $\mathrm{km}^{2}$ ):

$\mathrm{S}(0)=\left[\begin{array}{c}154366 \\ 215602 \\ 123089 \\ 89263\end{array}\right]=\left[\begin{array}{c}\text { No drought } \\ \text { Mild drought } \\ \text { Moderate drought } \\ \text { Severe/extreme drought }\end{array}\right]$

The second step is to determine the transition probability matrix. From table 2, the drought type transition probability matrix can be calculated for each transition from a year to another year. Then, average transition probability matrix is also calculated. In table 4 , the transition probability matrix from 2005 to 2006 is presented and the average transition probability matrix of all these transitions 2005-2006, 2006-2007, 2007-2008, 2008-2009, and 2009-2010 is given in table 5 .

According to the analysis of the transition probability matrix, it is observed that a state 'severe/extreme drought' would follow a state 'severe/extreme drought' with a probability of 0.893 , which is very high in comparison to other transitions.

States 'no drought', 'mild drought', and 'moderate drought' follow state 'no drought' with a probability of $0.770,0.211$, and 0.016 , respectively. After a state 'moderate drought', the chance of a state 'moderate drought' would be high in comparison to other states with a probability of 0.502 , and follows state 'severe/extreme drought' with a probability of 0.386 , which is important compared to probabilities of transition to states 'no drought' and 'mild drought'. State 'mild drought' is more likely to pass to state 'mild drought' and 'moderate drought' with a probability of 0.769 and 0.122 , respectively. Therefore, this analysis shows that the trend to pass to driest states is dominant.

\subsection{Evolution trends simulation}

In this section, the future drought distribution area in northern Algeria of change trend is estimated using equation (3). The simulation results are depicted in figure 3 and corresponding values are presented in table 6 .

In table 6 , the results indicated that the distribution area of no drought, mild drought, moderate drought, and severe/extreme drought will be in a stable state after 2041. The results show that the probability of class severe/extreme drought increases considerably rising from the probability

Table 4. Transition probability matrix from 2005 to 2006.

\begin{tabular}{lcccc}
\hline & \multicolumn{3}{c}{2006} \\
\cline { 2 - 5 } 2005 & $\begin{array}{c}\text { No } \\
\text { drought }\end{array}$ & $\begin{array}{c}\text { Mild } \\
\text { drought }\end{array}$ & $\begin{array}{c}\text { Moderate } \\
\text { drought }\end{array}$ & $\begin{array}{c}\text { Severe/extreme } \\
\text { drought }\end{array}$ \\
\hline No drought & 0.774 & 0.214 & 0.011 & 0.001 \\
Mild drought & 0.075 & 0.788 & 0.105 & 0.032 \\
Moderate drought & 0.055 & 0.088 & 0.492 & 0.365 \\
Severe/extreme drought & 0.050 & 0.056 & 0.072 & 0.882 \\
\hline
\end{tabular}

Table 5. Average transition probability matrix.

\begin{tabular}{lcccc}
\hline & $\begin{array}{c}\text { No } \\
\text { drought }\end{array}$ & $\begin{array}{c}\text { Mild } \\
\text { drought }\end{array}$ & $\begin{array}{c}\text { Moderate } \\
\text { drought }\end{array}$ & $\begin{array}{c}\text { Severe/extreme } \\
\text { drought }\end{array}$ \\
\hline No drought & 0.770 & 0.211 & 0.016 & 0.003 \\
Mild drought & 0.061 & 0.769 & 0.122 & 0.048 \\
Moderate drought & 0.050 & 0.062 & 0.502 & 0.386 \\
Severe/extreme drought & 0.010 & 0.022 & 0.075 & 0.893 \\
\hline
\end{tabular}




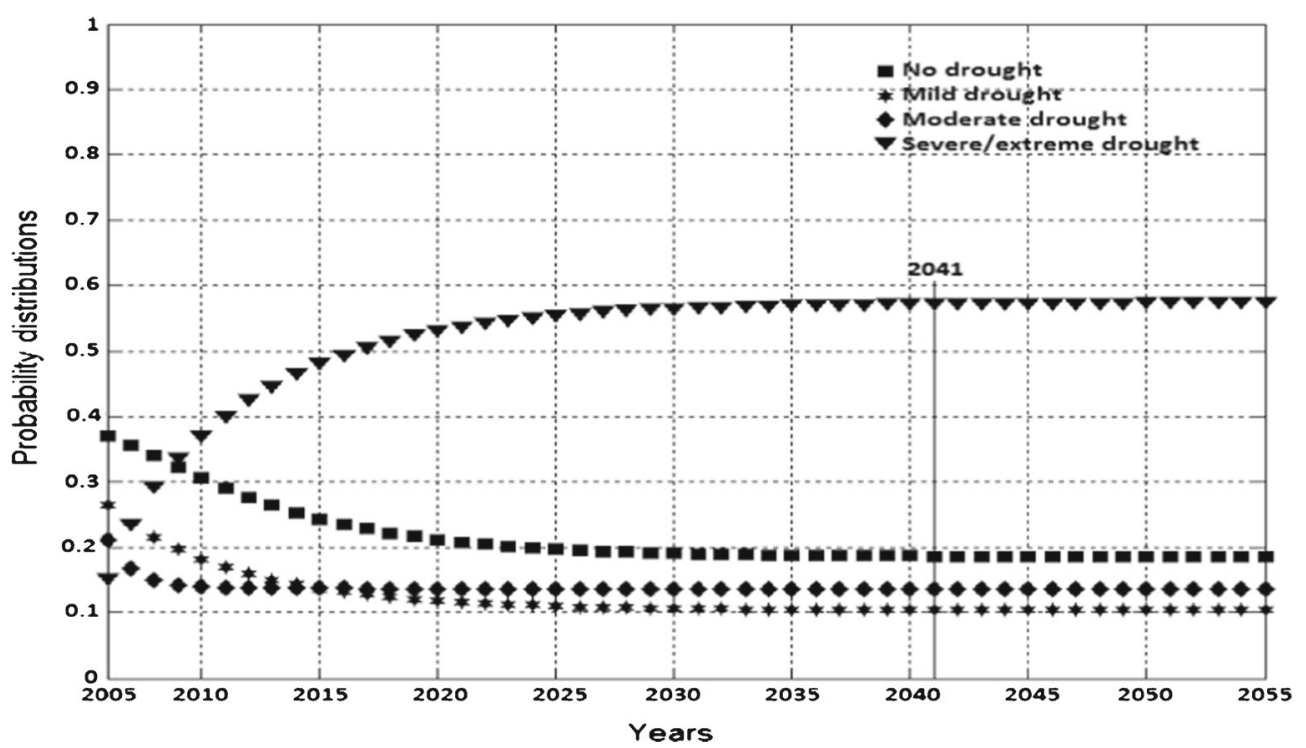

Figure 3. Evolution of probability distribution.

Table 6. Drought distribution area value estimated by using Markov chains.

\begin{tabular}{|c|c|c|c|c|c|c|c|c|}
\hline \multirow[b]{2}{*}{ Year } & \multicolumn{2}{|c|}{ No drought } & \multicolumn{2}{|c|}{ Mild drought } & \multicolumn{2}{|c|}{ Moderate drought } & \multicolumn{2}{|c|}{ Severe/extreme drought } \\
\hline & Probability & Area $\left(\mathrm{km}^{2}\right)$ & Probability & $\overline{\text { Area }\left(\mathrm{km}^{2}\right)}$ & Probability & $\overline{\text { Area }\left(\mathrm{km}^{2}\right)}$ & Probability & Area $\left(\mathrm{km}^{2}\right)$ \\
\hline 2011 & 0.1588 & 92472 & 0.2767 & 161128 & 0.1376 & 80127 & 0.4268 & 248593 \\
\hline 2012 & 0.1501 & 87406 & 0.2642 & 153849 & 0.1374 & 80011 & 0.4482 & 261054 \\
\hline 2015 & 0.1318 & 76750 & 0.2354 & 137078 & 0.1369 & 79719 & 0.4959 & 288773 \\
\hline 2020 & 0.1160 & 67549 & 0.2083 & 121297 & 0.1362 & 79311 & 0.5395 & 314163 \\
\hline 2030 & 0.1058 & 61609 & 0.1902 & 110757 & 0.1356 & 78962 & 0.5684 & 330992 \\
\hline 2040 & 0.1038 & 60445 & 0.1865 & 108602 & 0.1355 & 78904 & 0.5743 & 334369 \\
\hline 2041 & 0.1033 & 60157 & 0.1856 & 108078 & 0.1355 & 78904 & 0.5756 & 335181 \\
\hline 2042 & 0.1033 & 60157 & 0.1856 & 108078 & 0.1355 & 78904 & 0.5756 & 335181 \\
\hline 2045 & 0.1033 & 60157 & 0.1856 & 108078 & 0.1355 & 78904 & 0.5756 & 335181 \\
\hline 2050 & 0.1033 & 60157 & 0.1856 & 108078 & 0.1355 & 78904 & 0.5756 & 335181 \\
\hline 2055 & 0.1033 & 60157 & 0.1856 & 108078 & 0.1355 & 78904 & 0.5756 & 335181 \\
\hline$\rightarrow \infty$ & 0.1033 & 60157 & 0.1856 & 108078 & 0.1355 & 78904 & 0.5756 & 335181 \\
\hline
\end{tabular}

of 0.2650 in 2005 to a stable probability of 0.5756 in 2041 .

\subsection{Validation of Markov simulation model}

To validate Markov model, a comparison is carried out between the simulated and actual values of drought area in 2011 and 2012. For each year, the value of the chi-square $\left(\chi^{2}\right)$ statistic is computed based on the null hypothesis $\mathrm{H}_{0}$. The method of computing the $\chi^{2}$ for testing serial independence against Markovian property is extensively discussed in Wilks (2006). In the present study, the degrees of freedom would be 3 (4 categories -1 ). At this degree of freedom, the critical value in the test $(0.05)$ is 7.82 . The null hypothesis is rejected whenever the computed $\chi^{2}$ exceeds the critical value (7.82). Otherwise, the model is considered plausible.
The test of $\chi_{(0.05)}^{2}$ was applied between both values (estimated and actual) to evaluate the $95 \%$ significance of the results and thus to determine if the model is applicable or not. Test results have been calculated with equation (5) and are given in table 7 with actual values and estimated values for the years 2011 and 2012:

$$
\chi_{(0.05)}^{2}=\sum_{\mathrm{i}=1}^{4} \frac{\left(\mathrm{AV}_{\mathrm{i}}-\mathrm{EV}_{\mathrm{i}}\right)^{2}}{\mathrm{EV}_{\mathrm{i}}}
$$

where $E V_{i}$ and $A V_{i}$ are the values estimated by the model and the actual values, respectively.

The values of the $\chi_{(0.05)}^{2}$ test are lower than 7.82 for the two years (2011 and 2012), indicating that the estimated areas and the actual areas are almost identical. These results validate the Markov model which is used for modelling the chronological 
Table 7. Estimated model $\chi_{(0.05)}^{2}$ test using the drought distribution area in 2011 and 2012.

\begin{tabular}{|c|c|c|c|c|c|c|}
\hline & \multicolumn{3}{|c|}{2011} & \multicolumn{3}{|c|}{2012} \\
\hline & $\begin{array}{c}\text { Actual } \\
\text { values }\left(\mathrm{km}^{2}\right)\end{array}$ & $\begin{array}{c}\text { Estimated } \\
\text { values }\left(\mathrm{km}^{2}\right)\end{array}$ & $\begin{array}{c}\text { Absolute } \\
\text { error }\left(\mathrm{km}^{2}\right)\end{array}$ & $\begin{array}{c}\text { Actual } \\
\text { values }\left(\mathrm{km}^{2}\right)\end{array}$ & $\begin{array}{c}\text { Estimated } \\
\text { values }\left(\mathrm{km}^{2}\right)\end{array}$ & $\begin{array}{c}\text { Absolute } \\
\text { error }\left(\mathrm{km}^{2}\right)\end{array}$ \\
\hline No drought & 92508 & 92472 & 36 & 87452 & 87406 & 46 \\
\hline Mild drought & 161174 & 161128 & 46 & 153894 & 153849 & 45 \\
\hline Moderate drought & 80102 & 80127 & 25 & 79990 & 80011 & 21 \\
\hline Severe/extreme drought & 248536 & 248593 & 57 & 260984 & 261054 & 70 \\
\hline$\chi_{(0.05)}^{2}$ test & & 0.048 & & & 0.062 & \\
\hline
\end{tabular}
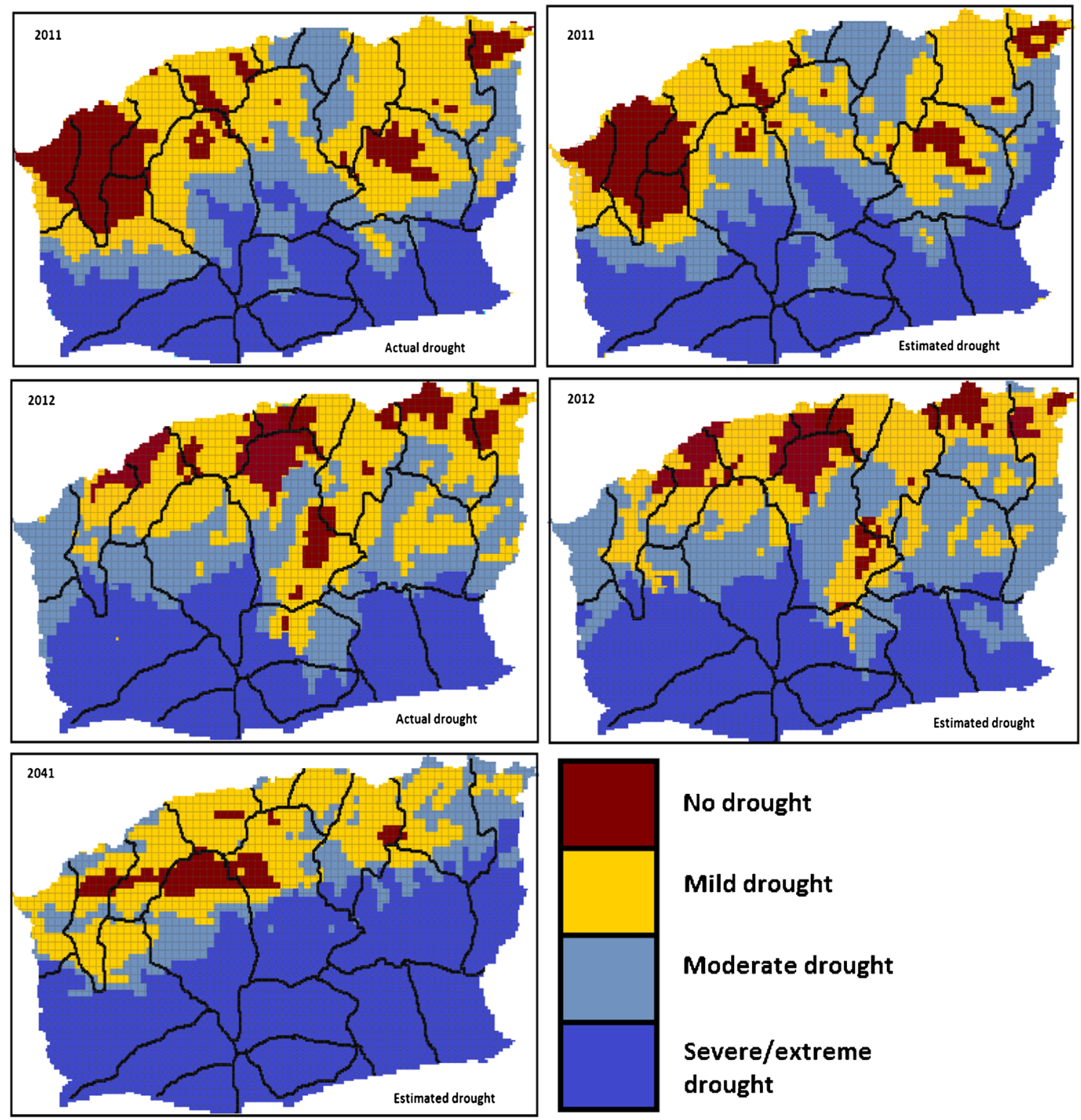

Figure 4. Maps of estimated and actual drought.

behaviour drought with four states. Therefore, the estimation of the evolution of drought distribution in the study area presented previously is plausible.

Also, in order to examine the spatial distribution that is important, maps of simulated and actual drought are constructed. The estimated droughts are performed at the resolution of SEVIRI pixel for spatial comparison. A pixel is simulated from probability vector of its previous state with probability matrix using Markov theorem (equation 3). 
The pixel is assigned to one category (no drought, mild drought, moderate drought or severe/extreme drought) according to the probability vector result. Indeed, this pixel is assigned to a category whose probability is the largest. The results of simulated and actual drought for years 2011 and 2012 are given in figure 4 . The map of simulated drought of the year 2041 is also constructed (figure 4).

Visibly, for the years 2011 and 2012, the map of estimated drought is similar to that of actual drought, in agreement with the comparison statistics found previously. Indeed, locations and magnitudes of local drought maxima in estimated maps coincide with those of actual maps. Even though this drought distribution is reproduced well, a significant overestimation of drought is evident across the study area. On the simulated map of the year 2041, it is shown that the severe drought category has reached more than $50 \%$ of the study area.

Moreover, according to this drought distribution area calculated using the Markov model carried out in this study, if the level of drought management of the last years in northern Algeria is maintained; the drought distribution area will be in net increase the next 30 years. From table 6 , the total drought area will be $522,163 \mathrm{~km}^{2}$, of which $64 \%$ is the class of severe/extreme drought in 2041. Compared to 2005, there will be an increase of $375 \%$ for severe/extreme drought and a decrease of $61 \%$ for no drought. These proportions are very disturbing.

In addition, from used data, it could be observed that the major part of drought occurred in the south of the study area. If this trend continues with this pace, northern Algeria will be affected seriously. Hence, it can be concluded that, with the available data, there is an evidence of a trend for increased drought frequency and severity in northern Algeria that could be attributed to climate change. Indeed, over the past 40 years, the ecosystem has been completely changed, both in its composition and in its functioning through its primary productivity. From all these results, it is clear that drought intensifies, indicated by the probability of 0.4268 for severe/extreme drought class, 0.1376 for moderate drought, 0.2767 for mild drought in 2011 and is likely to move to probabilities $0.5756,0.1355$, and 0.1856 for severe/extreme drought, moderate drought and mild drought in 2041, respectively. Also, the no drought class decreases from probability of 0.1588 in 2011 to 0.1033 in 2014. The results have highlighted a dangerous gradual silting up of drought from the south to the north in some areas. With this trend indicated by the probabilities (0.5756 for severe/extreme drought in 2041), the desertification, land degradation, and drought will be more pronounced in the future decades, posing fundamental problems and challenges for dryland populations, nations and regions in particular. This alarming situation must be taken into account.

\section{Conclusions}

The aim of this paper is the analysis of drought areas in northern Algeria using Markov chains. The Markov model is used to estimate future drought values on the basis of past precipitation. On annual precipitation maps over northern Algeria, drought categories are classified according to SPI values. Indeed, four states describing the drought intensities, namely no drought, mild drought, moderate drought, severe/extreme drought have been selected. Stochastic methodology to compute drought transition probabilities is presented.

The analysis presented here using Markov model is useful in understanding the stochastic characteristics of droughts through the analysis of probabilities for each severity class. Indeed, drought monitoring and forecasting are essential tools for implementing appropriate mitigation measures in order to reduce negative impacts. Knowledge of transition probabilities from a drought class to another, for a given site or region, as well as the availability of forecasts of drought indices, and of the related confidence intervals, can help to improve the decision making process for drought mitigation, since appropriate measures can be selected based on the risk associated with the possible evolution of a current drought condition.

Moreover, by responding to the hydrological needs in Algeria, the work conducted here presents an important contribution to the evaluation and quantification of water throughout the Algerian territory. Due to the Algerian climate, which becomes increasingly dry, this work provides information necessary for a rational and optimal allocation of water resources for sustainable development of areas relating to the agriculture and the needs of the population. The knowledge of rain fields in time and space is a significant parameter in the management of water resources.

To perform a more reliable analysis, it is preferable to consider a large database. Indeed, the transition matrix will be more representative of change in drought trends and therefore, the analysis will be more accurate. Further validation of the adopted stochastic model approaches using more data could be helpful to clearly describe and understand the behaviour of the drought.

\section{References}

Alexandrian D, Esnault F and Calabri G 1999 Forest fires in Mediterranean area; Unasylva 50 35-41. 
Cancelliere A, Mauro G Di, Bonaccorso B and Rossi G 2007 Drought forecasting using the Standardized Precipitation Index; Water Resour. Manag. 21 801-819.

Caskey J E 1963 Markov chain model for the probability of precipitation occurrence in intervals of various length; Mon. Wea. Rev. 91 298-301.

Chattopadhyay S, Acharya N, Chattopadhyay G, Kiran Prasad S and Mohanty U C 2012 Markov chain model to study the occurrence of pre-monsoon thunder storms over Bhubaneswar, India; Comptes Rendus Geoscience 344(10) 473-482.

Chin E H 1977 Modelling daily precipitation process with Markov chain; Water Resour. Res. 13 949-956.

Çinlar E 1975 Introduction to Stochastic Processes; Prentice Hall, New Jersey.

De Luis M, Ravent O S, Gonzalez-Hidalgo J, Sanchez J C and Cortina J 2000 Spatial analysis of rainfall trends in the region of Valencia (East Spain); Int. J. Climatol. 20 1451-1469.

Gabriel K R and Neumann J 1962 A Markov chain model for daily rainfall occurrence at Tel Aviv; Quart. J. Roy. Meterol. Soc. 88 90-95.

Hayes M J, Svoboda M, Wilhite D A and Vanyarkho O 1999 Monitoring the drought using the SPI; Bull. Am. Meteor. Soc. 80 429-438.

Lazri M, Ameur S and Haddad B 2007 Analyse de Données de Précipitations par Approche Markovienne; Larhyss J. 6 7-20.

Lazri M, Ameur Z, Ameur S, Mohia Y, Brucker J M and Testud J 2013 Rainfall estimation over a Mediterranean region using a method based on various spectral parameters of SEVIRI-MSG; J. Adv. Space Res., doi: 10.1016/j.asr.2013.07.036.

Lennartsson J, Baxevani A and Chen D 2008 Modelling precipitation in Sweden using multiple step Markov chains and a composite model; J. Hydrol. 363 42-59.

McKee T B, Doesken N J and Kleist J 1993 The relationship of drought frequency and duration to time scales; In: Proceedings of the Eighth Conference on Applied Climatology, Am. Meteor. Soc. Boston, pp. 179-184.
McKee T B, Doesken N J and Kleist J 1995 Drought monitoring with multiple time scales; In: Proceedings of the Ninth Conference on Applied Climatology, Am. Meteor. Soc. Boston, pp. 233-236.

Mehrotra R and Sharma A 2005 A non-parametric nonhomogeneous hidden Markov model for downscaling of multi-site daily rainfall occurrences; J. Geophys. Res. 110 D16108, doi: 10.1029/2004JD00567.

Mehrotra R, Srikanthan R and Sharma A 2006 A comparison of three stochastic multi-site precipitation occurrence generators; J. Hydrol. 331 280-292.

Moon S E, Ryoo S B and Kwon J G 1994 A Markov chain model for daily precipitation occurrence in South Korea; Int. J. Climatol. 14 1009-1016.

Moreira Elsa E, Ana A Paulo, Luís S Pereira and João T Mexia 2006 Analysis of SPI drought class transitions using loglinear models; J. Hydrol. 331 349-359.

Moreira Elsa E, Carlos A Coelho, Ana A Paulo, Luís S Pereira and João T Mexia 2008 SPI-based drought category prediction using loglinear models; J. Hydrol. 354 116-130.

Paulo Ana A and Luis S Pereira 2007 Prediction of SPI drought class transitions using Markov chains; Water Resour. Manag. 21 1813-1827.

Srikanthan R and McMahon T A 2001 Stochastic generation of annual, monthly and daily climate data: A review; Hydrol. Earth Syst. Sci. 5(4) 653-670.

Stern R D and Coe R 1984 A model fitting analysis of daily rainfall data; J. Roy. Stat. Soc. A 147(Part 1) $1-34$.

Weiss L L 1964 Sequences of wet or dry days described by a Markov chain probability model; Mon. Wea. Rev. 92 169-176.

Wilks D S 2006 Statistical Methods in the Atmospheric Sciences, 2nd edn, vol. 59, Academic Press, International Geophysics Series, 627p.

Yoo J, Kwon Hyun-Han, Tae-Woong Kim and Jae-Hyun Ahn 2012 Drought frequency analysis using cluster analysis and bivariate probability distribution; J. Hydrol. 420-421 102-111. 